(51) D. Guggi, H. Ihle, A. Neubert, and R. Woelfle, Radcat: Effects of Tritium Technology on Fusion Reactions, Proceedings of the International Conference, 3, 416 (1976)

(52) O.S. Popkov and G. A. Semenov, Zh. Fiz. Khim., 45, 476 (1971),

(53) J. Berkowitz, W. A. Chupka, G. D. Blue, and J. L. Margrave, J. Phys. Chem., 63, 644 (1959).

(54) D. White, R. S. Seshadri, D. F. Dever, D. E. Mann, and M. J. Linevsky, J. Chem. Phys., 39, 2463 (1963)

(55) D. L. Hildenbrand, W. F. Hall, and N. D. Potter, J. Chem. Phys., 39 296 (1963).

(56) L. P. Firsova and A. N. Nesmayanov, Russ. J. Phys. Chem, 34 $1232(1960)$.

(57) L. Brewer, Chem. Rev., 52, 1 (1953).

(58) A. Buechler, J. L. Stauffer, W. Klemperer, and L. Wharton, J. Chem Phys., 39, 2299 (1963).

(59) L. Brewer and J. L. Margrave, J. Chem. Phys., 59, 421 (1955)

(60) E. L. Wagner, Theor. Chim. Acta, 32, 295 (1974).

(61) J. M. King, Report EPRI, EM-576, Project 114-2 (1977).

(62) D. E. Jensen and P. J. Padley, Trans Faraday SoC, 62, 2132 (1966).

(63) D. H. Cotton and D. F. Jenkins, Trans. Faraday Soc., 65, 1537 (1969)

(64) M. J. McEwan and L. F. Phillips, Combust. Flame, 9, 457 (1960).

(65) E. K. Belyaev and V. F. Annopol'skii, Zh. Neorg. Khim., 17, 2072 (1972).
(66) V. F. Annopol'skii, E. K. Belyaev, and I. P. Knigovko, Zh. Neorg, Khim., 20, 298 (1975).

(67) R. C. Doman and R. N. McNally, J. Mater. Scl., 8, 189 (1973).

(68) H. Schwarzer and H. Neels, Krist. Tech., 6, 639 (1971).

(69) N. N. Efimova and Yu. A. Mamalui, Ukr. Fiz. Zh., 20, 1201 (1975).

(70) P. M. Jaffe, J. Electrochem. Soc., 115, 1203 (1968).

(71) G. T. Pott and B. D. McNichol, Chem. Phys. Lett., 12, 52 (1971); J. Sold State Chem., 7, 132 (1973); J. Chem. Phys., 56, 5246 (1972); J. Lumin., 6, $320(1973)$

(72) M. N. Baranov and E. F. Kustov, Opt. Spektrosk., 34, 726 (1973).

(73) W. H. J. Stork and G. T. Pott, J. Phys. Chem., 78, 2496 (1974).

(74) W. P. Petrov, H. Szymczak, R. Wades, and W. Wardzynski, J. Phys. (Paris), 32, Suppl. 847 (1971).

(75) H. P. Fritzer, E. Sliuc, and K. Torkar, Monatsh. Chem., 104, 172 (1973).

(76) A. Fruma, D. Ciomartan, J. Brasoveanu, and I. V. Nicolescu, Rev. Roum. Chim., 18, 803 (1973).

(77) N. F. Ermolenko, M. D. Efror, and A. V. Oboturov, Absorbenty. Ikh. Poluch., Svoistva Primen. Tr. Vses. Soveshch. Adsorbentam, 3rd, $1969,83(1971)$

(78) R. T. Cox, Solid State Commun., 9, 1989 (197 1).

(79) V. A. Kolesova, Zh. Neorg. Khim., 19, 2898 (1974).

(80) R. Happe and H. Koenig, Z. Anorg. Allg. Chem., 430, 211 (1977).

\title{
Thermochemical Investigations of Nearly Ideal Binary Solvents. 4. Gas-Liquid Partition Coefficients in Complexing and Noncomplexing Systems
}

\author{
WIlliam E. Acree, Jr., and Gary L. Bertrand* \\ Department of Chemistry, University of Missouri-Rolla, Rolla, Missouri 65401 (Received January 11, 1979) \\ Publication costs assisted by the National Sclence Foundation
}

\begin{abstract}
The nearly ideal binary solvent (NIBS) approximation is applied to gas-liquid partition coefficients derived from gas-liquid chromatographic experiments with a mixed liquid phase. For the noncomplexing systems studied to date, the resulting equation can be reduced to the empirical equation in which partition coefficients in binary systems are linear with volume fraction. Extension of this model to a system with a 1:1 solvent-solute complex results in an equation which can also be reduced to the linear form in some circumstances. The linear relationship between volume fraction and the partition coefficient of a solute in a binary solvent is demonstrated to be a nongeneral thermodynamic relationship.
\end{abstract}

\begin{abstract}
Gas-liquid chromatographic studies with a mixed liquid phase provide a relatively simple, but quite accurate tool for determining thermodynamic properties of a solute near infinite dilution. Of particular interest has been the application of this tool to the study of association complexes between the solute and one of the solvent components. Martire ${ }^{1}$ has shown that the equilibrium constant for complex formation cannot be separated from the effects of noncomplexing solvent-solute interactions in studies with the complexing solvent at high dilution. His model led to an equation predicting curvature in plots of the infinite dilution partition coefficient of the solute $\left(K_{\mathrm{R}}{ }^{\circ}\right)$ against the volume fraction of complexing solvent $\left(\phi_{\mathrm{B}}\right)$, though the curvature might be insignificant in comparison to experimental error. Eon, Pommier, and Guiochon ${ }^{2}$ developed an equation which can be reduced to a linear relationship between the partition coefficient and volume fraction of the complexing solvent over the complete range of solvent compositions for a "quasi-ideal" solvent. However, Purnell and co-workers ${ }^{3-5}$ have shown that the linear relationship between volume fraction and partition coefficient is obeyed, almost without exception, in all of the binary systems studied, irrespective of the complexing nature of the solvents, and suggest that this may imply "the prospect of a coherent theory of solutions of a gen-
\end{abstract}

erality not hitherto visualized". 3

In this paper, we demonstrate that the linear relationship between the partition coefficient of a solute (A) in a mixture $(M)$ of solvents $(B, C)$ with volume fraction, while perhaps an adequate description of the systems studied to date, does not represent a general thermodynamic relationship. We also show that a simple but realistic model leads to an equation which closely approximates eq 1 for the noncomplexing systems which have

$$
\left(K_{\mathrm{R}}{ }^{\circ}\right)_{\mathrm{M}}=\phi_{\mathrm{B}}\left(K_{\mathrm{R}}{ }^{\circ}\right)_{\mathrm{B}}+\phi_{\mathrm{C}}\left(K_{\mathrm{R}}{ }^{\circ}\right)_{\mathrm{C}}
$$

been studied to date, and may be extended to a similar form for complexing sytems. This model has been shown to be quite useful in predicting heats of solution ${ }^{6}$ and solubilities ${ }^{7}$ in systems with nonspecific interactions, and an expanded form has been used to explain solubility in complexing systems. ${ }^{8}$

\section{Demonstration of the Nongenerality of Eq 1}

Gas-liquid partition coefficients can be related to other thermodynamic properties through the definition

$$
K_{\mathrm{R}}{ }^{\circ}=\frac{R T Q}{\bar{V}_{\mathrm{M}} p_{\mathrm{A}}{ }^{\circ} \gamma_{\mathrm{A}}{ }^{\infty}}
$$

in which $p_{A}{ }^{\circ}$ is the equilibrium vapor pressure of the solute 
at the specified temperature, $\bar{V}_{\mathrm{M}}$ is the molar volume of the pure or mixed solvent, $\gamma_{A}{ }^{\infty}$ is the activity coefficient (relative to Raoult's law) of the solute at infinite dilution, and $Q$ is a temperature-dependent term involving the molar volume of the pure liquid solute and the second virial coefficients of the solute and the carrier gas. Using this relationship, Purnell and Vargas de Andrade have shown ${ }^{5}$ that eq 1 is equivalent to

$$
\frac{1}{\left(\gamma_{\mathrm{A}}{ }^{\infty}\right)_{\mathrm{M}}}=\frac{x_{\mathrm{B}}}{\left(\gamma_{\mathrm{A}}{ }^{\infty}\right)_{\mathrm{B}}}+\frac{x_{\mathrm{C}}}{\left(\gamma_{\mathrm{A}}\right)_{\mathrm{C}}}
$$

where $x_{i}$ is the mole fraction, with only the approximation that the excess molar volume of the solvent mixture is negligible. Complete generality of eq 1 implies complete generality of eq 3 , within the limitations of the ideal molar volume approximation. The nongenerality of eq 3 can be demonstrated by consideration of solubility in binary solvents.

The activity coefficient of the solute can be related to the solubility of a solid through the relationship

$$
a_{\mathrm{A}}^{\text {solid }}=x_{\mathrm{A}}^{\text {satd }} \gamma_{\mathrm{A}}^{\text {satd }}
$$

in which the activity of the solid depends on temperature only, and is determined relative to the pure supercooled liquid. If the solubility is sufficiently small, the activity coefficient at infinite dilution may be approximated directly as the activity coefficient at saturation, or through the approximation

$$
\ln \gamma_{\mathrm{A}}^{\text {satd }}=\left(1-x_{\mathrm{A}}^{\text {satd }}\right)^{2} \ln \gamma_{\mathrm{A}}^{\infty}
$$

Combination of eq $3-5$ gives

$$
\left(x_{\mathrm{A}}^{\mathrm{satd}}\right)_{\mathrm{M}}=x_{\mathrm{B}}\left(x_{\mathrm{A}}^{\mathrm{satd}}\right)_{\mathrm{B}}+x_{\mathrm{C}}\left(x_{\mathrm{A}}^{\text {satd }}\right)_{\mathrm{C}}
$$

which is quite similar to an equation developed by Sytilin ${ }^{9}$ for description of the solubility of iodine in mixed solvents

$$
\begin{gathered}
\left(C_{\mathrm{A}}^{\text {satd }}\right)_{\mathrm{M}}=K_{\mathrm{B}} C_{\mathrm{B}}+K_{\mathrm{C}} C_{\mathrm{C}} \\
K_{\mathrm{i}}=\left(C_{\mathrm{A}}^{\text {satd }}\right)_{\mathrm{i}} / C_{\mathrm{i}}^{0} \quad \mathrm{i}=\mathrm{B}, \mathrm{C}
\end{gathered}
$$

in which $C$ is concentration in moles/liter, and $C_{i}^{0}$ is the concentration of a pure solvent. With the approximate relationship

$$
C_{\mathrm{i}}=10^{3} x_{\mathrm{i}} /\left(x_{\mathrm{B}} \bar{V}_{\mathrm{B}}+x_{\mathrm{C}} \bar{V}_{\mathrm{C}}\right)
$$

eq 7 becomes identical with eq 6 . Sytilin's equation is based on the assumption of solvational complexes, and is applied to many systems in which true association is not expected, as in iodine + alkane mixtures. While there is little theoretical justification for this equation, there are nonetheless a rather large number of systems for which this is a reasonable approximation. We have observed, however, that Sytilin's equation is a good approximation for complexing and noncomplexing systems in which the molar volume of the solute is small in comparison to the molar volumes of the solvents, but that the approximation becomes increasingly less accurate with increasing solute size relative to the solvents. A classic violation of eq 6 is found in the study of phenanthrene in mixtures of cyclohexane and methylene iodide ${ }^{10}$ in which the solubility shows a maximum value which is almost twice that predicted by eq 6 . It is difficult to attribute this failure of eq 6 to complexation or to departure from infinite dilution, since the existence of maximum solubility in this system is predicted by solubility parameter theory.

Another flaw in the generality of eq 3 and eq 1 becomes apparent on differentiation with respect to temperature. Using the thermodynamic relationship

$$
\begin{aligned}
&\left(\partial \ln \gamma_{\mathrm{A}}{ }^{\infty} / \partial T\right)_{P, x_{\mathrm{B}}}=\left(1 / \gamma_{\mathrm{A}}{ }^{\infty}\right)\left(\partial \gamma_{\mathrm{A}}{ }^{\infty} / \partial T\right)_{P, x_{\mathrm{B}}}= \\
&-\left(\Delta H_{\mathrm{A}}{ }^{\circ}\right)_{\mathrm{M}} R^{-1} T^{-2}
\end{aligned}
$$

in which $\left(\Delta H_{\mathrm{A}}{ }^{\circ}\right)_{\mathrm{M}}$ is the standard enthalpy of solution (at infinite dilution) in the pure or mixed solvent, one finds that this differentiation gives

$$
\begin{aligned}
& \left(\Delta H_{\mathrm{A}}{ }^{\circ}\right)_{\mathrm{M}}=g_{\mathrm{B}}\left(\Delta H_{\mathrm{A}}{ }^{\circ}\right)_{\mathrm{B}}+g_{\mathrm{C}}\left(\Delta H_{\mathrm{A}}{ }^{\circ}\right)_{\mathrm{C}} \\
& g_{\mathrm{B}}=\left(1-g_{\mathrm{C}}\right)=\frac{x_{\mathrm{B}}\left(\gamma_{\mathrm{A}}^{\infty}\right)_{\mathrm{C}}}{x_{\mathrm{B}}\left(\gamma_{\mathrm{A}}^{\infty}\right)_{\mathrm{C}}+x_{\mathrm{C}}\left(\gamma_{\mathrm{A}}{ }^{\infty}\right)_{\mathrm{B}}}
\end{aligned}
$$

While there is insufficient data to test eq 10 in many systems, this equation is obviously incapable of describing a system in which the enthalpy of solution shows a maximum or minimum value. However, very pronounced maxima are observed for enthalpies of solution in aqueous organic solvent mixtures, and minima have been observed in systems for which only nonspecific interactions are expected, as in the study of squalane in mixtures of carbon tetrachloride and cyclohexane. ${ }^{6}$ This latter observation is in agreement with our earlier observation regarding solubilities in systems of nonspecific interactions, in that eq 3 fails for a solute which is relatively large in comparison to the solvents. Obvious failures of this type have not been noted in GLC studies of gas-liquid partition, perhaps because these studies normally involve solvents which are much larger than the solutes. The thermodynamic consequence of eq 1 , eq 3 , is clearly not a general thermodynamic relationship for noncomplexing systems.

\section{Nearly Ideal Binary Solvent (NIBS) Approach to Gas-Liquid Partition Coefficients in Noncomplexing Systems}

Using a simple model equation for the excess Gibbs free energy of a multicomponent system

$$
\begin{gathered}
\Delta G^{\text {mixing }}=R T \sum_{\mathrm{i}=1}^{N}\left(n_{\mathrm{i}} \ln \phi_{\mathrm{i}}\right)+\Delta G^{\mathrm{fh}} \\
\Delta G^{\mathrm{fh}}=\left(\sum_{\mathrm{i}=1}^{N} n_{\mathrm{i}} \bar{V}_{\mathrm{i}}^{0}\right) \sum_{\text {all pairs }} \phi_{\mathrm{i}} \phi_{\mathrm{j}} A_{\mathrm{ij}}
\end{gathered}
$$

we have developed an equation (eq VV, ref 7) with no adjustable parameters which predicts solubility in 22 systems of nonspecific interactions containing naphthalene, iodine, and stannic iodide as solutes with an average deviation of $1.5 \%$ and a maximum deviation of $4 \%$. Using the definitions

$$
\begin{gathered}
\Delta G^{\mathrm{fh}}=R T \sum_{\mathrm{i}=1}^{N} n_{\mathrm{i}} \ln \gamma_{\mathrm{i}}^{\mathrm{fh}} \\
\ln \gamma_{\mathrm{i}}^{\mathrm{fh}}=\ln \left(a_{\mathrm{i}} / \phi_{\mathrm{i}}\right)-\left(1-\frac{\bar{V}_{\mathrm{i}}}{\bar{V}_{\mathrm{M}}}\right) \\
\gamma_{\mathrm{i}}^{*}=\lim _{x_{\mathrm{i}} \rightarrow 0} \gamma_{\mathrm{i}}^{\text {fh }}
\end{gathered}
$$

we found that the equation for a solute at infinite dilution in a binary solvent takes the form

$\ln \gamma_{\mathrm{A}}^{*}=\phi_{\mathrm{B}} \ln \left(\gamma_{\mathrm{A}}^{*}\right)_{\mathrm{B}}+\phi_{\mathrm{C}} \ln \left(\gamma_{\mathrm{A}}^{*}\right)_{\mathrm{C}}-\frac{\bar{V}_{\mathrm{A}} \Delta \bar{G}_{\mathrm{BC}}^{\mathrm{fh}}}{\bar{V}_{\mathrm{M}} R T}$

in which $\Delta \bar{G}_{\mathrm{BC}}{ }^{\text {fh }}$ represents the excess Gibbs free energy (as defined in eq 11) per mole of the binary mixture of $B$ and $\mathrm{C}$. The ordinary activity coefficient $\left(\gamma_{1}{ }^{\infty}\right)$ is related to $\gamma_{1}^{*}$ by

$$
\gamma_{1}^{\infty}=\gamma_{1} * \frac{\bar{V}_{1}}{\bar{V}_{M}} \exp \left(1-\frac{\bar{V}_{1}}{\bar{V}_{M}}\right)
$$


and combination of eq 2,16 , and 17 gives

$$
\ln K_{\mathrm{R}}{ }^{\circ}=\phi_{\mathrm{B}} \ln \left(K_{\mathrm{R}}{ }^{\circ}\right)_{\mathrm{B}}+\phi_{\mathrm{C}} \ln \left(K_{\mathrm{R}}{ }^{\circ}\right)_{\mathrm{C}}+\frac{V_{\mathrm{A}} \bar{\Delta} G_{\mathrm{BC}}{ }^{\text {fh }}}{R T \bar{V}_{\mathrm{M}}}
$$

If the molar volume of the solute is small in comparison to the solvent, as is the usual case in GLC studies, and/or the excess free energy of the solvent pair as defined by eq 11 is small, the last term on the right-hand side of eq 18 becomes negligible giving

$$
\ln K_{\mathrm{R}}{ }^{\circ}=\phi_{\mathrm{B}} \ln \left(K_{\mathrm{R}}{ }^{\circ}\right)_{\mathrm{B}}+\phi_{\mathrm{C}} \ln \left(K_{\mathrm{R}}{ }^{\circ}\right)_{\mathrm{C}}
$$

For ratios of $\left(K_{\mathrm{R}}\right)_{\mathrm{B}} /\left(K_{\mathrm{R}}\right)_{\mathrm{C}}$ near unity, eq 19 is equivalent to eq 1 . Values of $K_{\mathrm{R}}$ calculated with eq 19 are within $1 \%$ of those calculated with eq 1 for ratios of partition coefficients in the pure solvents up to 1.3 , and values calculated from eq 19 are always less than those calculated from eq 1 , so that small positive values of $\Delta \bar{G}_{\mathrm{BC}}{ }^{\text {fh }}$ (as is expected in noncomplexing systems) improve the agreement between these two equations. Thus for the noncomplexing systems studied by the GLC method, eq 1 may be taken as a very good approximation of the more general eq 18 which is based on a realistic (though approximate) thermodynamic model. An equation similar to eq 18 has very recently been presented, ${ }^{11}$ using a specific model for the excess free energy of the binary solvent.

\section{Extension to Complexing Systems}

In the case of complexation between the solute and one of the solvents

$$
\mathrm{A}+\mathrm{C}=\mathrm{AC}
$$

the mixing model of eq 11 leads to an equilibrium constant of the form

$K_{\mathrm{a}}=\left(\phi_{\mathrm{AC}} / \phi_{\mathrm{A}} \phi_{\mathrm{C}}\right)\left(\gamma_{\mathrm{AC}} * / \gamma_{\mathrm{A}} * \gamma_{\mathrm{C}}{ }^{*}\right) \exp \left(-1-\frac{\Delta V}{\bar{V}_{\mathrm{M}}}\right)$

in which $\gamma_{A}{ }^{*}$ and $\phi_{A}$ refer to the uncomplexed solute and $\Delta V$ is the volume change on formation of $1 \mathrm{~mol}$ of complex, which is expected to be negligible. Assuming that the ratio of activity coefficients in eq 20 is constant for a given solvent pair, an operational equilibrium constant $K^{\prime}$ (related to the molar equilibrium constant, $K_{\mathrm{M}}$ ) can be defined in terms of the moles of complex and uncomplexed solute $\left(n_{\mathrm{AC}}, n_{\mathrm{A}}\right)$

$$
\begin{array}{r}
K^{\prime}=n_{\mathrm{AC}} / n_{\mathrm{A}} \phi_{\mathrm{C}}=K_{\mathrm{a}}\left(\bar{V}_{\mathrm{A}} / \bar{V}_{\mathrm{AC}}\right)\left(\gamma_{\mathrm{A}}^{*} \gamma_{\mathrm{C}}^{*} / \gamma_{\mathrm{AC}}^{*}\right)= \\
10^{3} K_{\mathrm{M}} / \bar{V}_{\mathrm{C}}
\end{array}
$$

so that the fraction of solute molecules which are not complexed is

$$
f_{\mathrm{A}}=\frac{n_{\mathrm{A}}}{\left(n_{\mathrm{A}}+n_{\mathrm{AC}}\right)}=\left(1+K^{\prime} \phi_{\mathrm{C}}\right)^{-1}
$$

The apparent activity coefficient for the solute $\left(\gamma_{\mathrm{A}}^{*}\right)^{\mathrm{app}}$ is then related to the activity coefficient of uncomplexed solute $\left(\gamma_{\mathrm{A}}^{*}\right)$ by

$$
\gamma_{\mathrm{A}}^{*}=\left(\gamma_{\mathrm{A}}^{*}\right)^{\mathrm{app}}\left(1+K^{\prime} \phi_{\mathrm{C}}\right)
$$

and

$$
\left(\gamma_{\mathrm{A}}^{*}\right)_{\mathrm{C}}=\left(\gamma_{\mathrm{A}}^{*}\right)_{\mathrm{C}}^{\mathrm{app}}(1+K)
$$

Substitution of eq 23 and 24 into eq 16 gives

$$
\begin{aligned}
\ln \left(\gamma_{\mathrm{A}}^{*}\right)^{\mathrm{app}}=\phi_{\mathrm{B}} \ln \left(\gamma_{\mathrm{A}}{ }^{*}\right)_{\mathrm{B}}+\phi_{\mathrm{C}} \ln \left(\gamma_{\mathrm{A}}{ }^{*}\right)_{\mathrm{C}}- \\
\frac{\bar{V}_{\mathrm{A}} \Delta \bar{G}_{\mathrm{BC}}}{\bar{V}_{\mathrm{M}} R T}-\ln \left(1+K^{\prime} \phi_{\mathrm{C}}\right)
\end{aligned}
$$

Combination of eq 2,17 , and 25 with the assumption that the binary mixing term is negligible gives

$$
\begin{array}{r}
\ln \left(K_{\mathrm{R}}{ }^{\circ}\right)_{\mathrm{M}}=\phi_{\mathrm{B}} \ln \left(K_{\mathrm{R}}{ }^{\circ}\right)_{\mathrm{B}}+\phi_{\mathrm{C}} \ln \left(K_{\mathrm{R}}{ }^{\prime}\right)_{\mathrm{C}}+ \\
\ln \left(1+K^{\prime} \phi_{\mathrm{C}}\right)
\end{array}
$$

in which $\left(K_{\mathrm{R}}{ }^{\prime}\right)_{\mathrm{C}}$ is the partition coefficient of the uncomplexed solute in pure solvent $\mathrm{C}$. Calculations with eq 26 with various values of $K^{\prime}$ and the ratio of partition coefficients of uncomplexed solute in the pure solvents show that $\left(K_{\mathrm{R}}{ }^{\circ}\right)_{\mathrm{M}}$ becomes increasingly linear with volume fraction as the ratio $\left(K_{\mathrm{R}}{ }^{\prime}\right)_{\mathrm{C}} /\left(K_{\mathrm{R}}{ }^{\circ}\right)_{\mathrm{B}}$ approaches unity. This unit ratio of partition coefficients has been assumed in previous calculations of complexation constants from partition coefficients. With this assumption, eq 26 becomes

$$
\left(K_{\mathrm{R}}{ }^{\circ}\right)_{\mathrm{M}}=\left(K_{\mathrm{R}}{ }^{\circ}\right)_{\mathrm{B}}\left(1+K^{\prime} \phi_{\mathrm{C}}\right)
$$

which is identical with eq 1 , with

$$
K^{\prime}=\frac{\left(K_{\mathrm{R}}^{0}\right)_{\mathrm{C}}-\left(K_{\mathrm{R}}{ }^{0}\right)_{\mathrm{B}}}{\left(K_{\mathrm{R}}{ }^{0}\right)_{\mathrm{B}}}
$$

This relationship was noted by Purnell and Vargas de Andrade. ${ }^{5}$

\section{Discussion}

Since eq 1 applies equally well to systems which are considered to be incapable of forming association complexes and to those in which complexes are known to exist, it is clear that meaningful association constants cannot be derived directly from this equation. Some estimate or approximation of the partition coefficient of uncomplexed solute in the complexing solvent is required to allow estimation of the association constant. Eon, Pommier, and Guichon ${ }^{2}$ incorporated the effect of the molar volume of the solvent on the partition coefficient of the solute (in mixtures and pure solvents), using an athermal FloryHuggins solution model.

This is essentially the same as assuming that the activity coefficient $\left(\gamma_{\mathrm{A}}^{*}\right)$ of the uncomplexed solute is the same in the pure solvents and all mixtures of the two. On the basis of the accuracy of eq 1 for a mixed solvent, it is impossible to determine the existence of a single solvent-solute complex. If this equation is obeyed, one must assume that either no complexation occurs or that a single complex is formed. If substantial deviations from this equation are observed, multiple complexes are assumed. Equation 19 however, clearly distinguishes between systems with no complexation and those with appreciable complexation. This equation gives excellent agreement with experiment (somewhat better than eq 1 , though both are probably within experimental uncertainty) for the $n$-alkane systems studied by Laub, Martire, and Purnell, ${ }^{3}$ and for two solutes (cyclopentane and diethyl ether) for which Eon, Pommier, and Guiochon assigned very small association constants in the squalane + dibutyl tetrachlorophthalate system, but the agreement for other solutes in this latter system is rather poor. Our use of eq 19 is a bit different from the manner in which eq 1 has previously been used. We consider the values in the pure solvents as essentially "perfect" numbers, and measure deviations between experimental values of $\left(K_{\mathrm{R}}^{\circ}\right)_{\mathrm{M}}$ determined in mixtures and the predictions of eq 19. We consider this a more demanding test than measurement of deviations of observed values from a linear curve-fit of eq 1 in which the pure solvent values are assigned the same weight as the values determined for mixtures.

For complexing systems, in terms of the partition coefficients in pure solvents, eq 26 takes the one-parameter $(K)$ form 


$$
\begin{aligned}
& \ln \left(K_{\mathrm{R}}{ }^{\circ}\right)_{\mathrm{M}}=\phi_{\mathrm{B}} \ln \left(K_{\mathrm{R}}{ }^{\circ}\right)_{\mathrm{B}}+\phi_{\mathrm{C}} \ln \left(K_{\mathrm{R}}{ }^{0}\right)_{\mathrm{C}}+ \\
& \ln \left(1+K^{\prime} \phi_{\mathrm{C}}\right)-\phi_{\mathrm{C}} \ln \left(1+K^{\prime}\right)+\frac{\bar{V}_{\mathrm{A}} \Delta \bar{G}_{\mathrm{BC}}{ }^{\text {fh }}}{\bar{V}_{\mathrm{M}} R T}
\end{aligned}
$$

Eon et al. have presented evidence for the ideality of the squalane + DBTC system, which justifies neglect of the last term of eq 29. In this equation, $K^{\prime}$ can be treated as an experimental parameter, with $\left(K_{\mathrm{R}}{ }^{\prime}\right)_{\mathrm{C}}$ not necessarily the same as $\left(K_{\mathrm{R}}{ }^{\circ}\right)_{\mathrm{B}}$, or as a fixed parameter with

$$
\left(K_{\mathrm{R}}\right)_{\mathrm{C}}=\left(K_{\mathrm{R}}{ }^{0}\right)_{\mathrm{B}}=\left(K_{\mathrm{R}}{ }^{0}\right)_{\mathrm{C}}\left(1+K^{\prime}\right)^{-1}
$$

These two treatments are essentially the same for all of the complexing solutes studied by Eon et al., with the exceptions of cyclopentene, diethyl ether, pyrrole, and 1-methylpyrrole.

For these first two exceptions, the difference is simply a question of whether $K^{\prime}$ is zero or some very small number. Eon et al. invoked multiple equilibria to account for the deviations of pyrrole and 1-methylpyrrole from eq 1 , and eq 29 with the restrictions of eq 30 is unable to properly describe these systems. However, without the restrictions of eq 30 , eq 29 can describe these systems very well with a single equilibrium constant, though the ratio of $\left(K_{\mathrm{R}}{ }^{\prime}\right)_{\mathrm{C}} /\left(K_{\mathrm{R}}{ }^{\circ}\right)_{\mathrm{B}}$ is substantially greater than unity for these systems. While one might argue that substantial deviation of the partition coefficient ratio for "uncomplexed" solute from unity in this "pseudo-ideal"2 solvent system is evidence of some degree of complexation, this merely points out the difficulty of separating "physical" and "chemical" solvent effects. ${ }^{12}$

In all of the systems studied thus far, lack of experimental mixing data for the binary solvent has necessitated the approximation of this term in eq 29 as zero. Because of the low volatility of these solvents (a necessary property for GLC applications), experimental mixing data are quite difficult to obtain. The magnitude of this term may be assessed through eq 29 for a solvent pair by measurement of partition coefficients of alkanes. Since these compounds are generally considered incapable of complex formation
$\left(K^{\prime}=0\right)$, deviations from eq 19 can be attributed to the mixing term in eq 18 or 29 . This mixing term involves only the molar volume of the solute and properties of the binary mixture, thus allowing evaluation of $\Delta \bar{G}^{\mathrm{fh}} / \bar{V} R T$ for a given solvent mixture from the partition coefficient of an alkane in this mixture and the pure solvents. This term can then be applied in eq 29 for studies of more complex solutes. For example, we consider the partition coefficients of alkanes and cycloalkanes in mixtures of squalane and dinonyl phthallate (DNP) at $30^{\circ} \mathrm{C}$, measured by Harbison et al. ${ }^{11}$ For these relatively inert solutes, eq 1 fails by $6-8 \%$ and eq 19 by $8-11 \%$. However, from their data at $\phi_{\mathrm{DNP}}$ $=0.452$, eq 18 can be used to estimate $\Delta \bar{G}_{\mathrm{BC}}{ }^{\text {fh }}$ at this composition. Values of $\Delta \bar{G}_{\mathrm{BC}}{ }^{\text {fh }}$ calculated for pentane, hexane, heptane, octane, cyclohexane, and methylcyclohexane range from 800 to $880 \mathrm{~J} / \mathrm{mol}$ ( $1 \%$ uncertainty in $K_{\mathrm{R}}{ }^{\circ}$ corresponds to about $100 \mathrm{~J} / \mathrm{mol}$ uncertainty in $\Delta \vec{G}_{\mathrm{BC}}^{(\mathrm{M})}$ ). Use of the average value $(840 \mathrm{~J} / \mathrm{mol})$ in eq 29 with data for benzene and toluene as solutes in this solvent mixture leads to molar equilibrium constants $\left(K_{\mathrm{M}}\right)$ of 0.22 and $0.17 \mathrm{~L} / \mathrm{mol}$, respectively, for complexes of benzene and toluene with DNP.

Acknowledgment. This work is supported by the National Science Foundation Grant CHE77-09885.

\section{References and Notes}

(1) D. E. Martire, Anal. Chem., 46, 1712 (1974)

(2) C. Eon, C. Pommier, and G. Gulochon, J. Phys. Chem., 75, 2632 (1971).

(3) R. J. Laub, D. E. Martire, and J. H. Purnell, J. Chem. Soc., Faraday Trans. 2, 213 (1978).

4) R. J. Laub and J. H. Purnell, J. Am. Chem. Soc., 98, 30 (1976),

(5) J. H. Purnell and J. M. Vargas de Andrade, J. Am. Chem. Soc., 97, 3585 (1975)

(6) T.E. Burchfield and G. L. Bertrand, J. Solution Chem., 4, 205 (1974).

(7) W. E. Acree, Jr., and G. L. Bertrand, J. Phys. Chem., 81, 1170 (1977).

(8) T. Nitta and T. Katayama, J. Chem. Eng. Jpn., 8, 175 (1975).

(9) M. S. Sytilin, Russ. J. Phys. Chem., 48, 1091, 1353, 1500 (1974).

(10) L J Gordon and R. L. Scott, J. Am. Chem. Soc., 74, 4138 (1952)

(11) M. W. P. Harbison, R. J. Laub, D. E. Martire, J. H. Purnell, and P. S. Williams, J. Phys. Chem., 83, 1262 (1979).

(12) G. L. Bertrand, J. Phys. Chem., 79, 48 (1975). 